\title{
Thymoquinone induces apoptosis through downregulation of c-FLIP and Bcl-2 in renal carcinoma Caki cells
}

\author{
EUN JUNG PARK ${ }^{1}$, ANIL KUMAR CHAUHAN ${ }^{1}$, KYOUNG-JIN MIN $^{1}$, \\ DONG CHEOL PARK ${ }^{2}$ and TAEG KYU KWON ${ }^{1}$ \\ ${ }^{1}$ Department of Immunology, School of Medicine, Keimyung University, Daegu 704-701; \\ ${ }^{2}$ Department of Hotel Cuisine and Food Service Management, Gimcheon University, \\ Gimcheon 39528, Republic of Korea
}

Received March 27, 2016; Accepted August 4, 2016

DOI: $10.3892 /$ or.2016.5019

\begin{abstract}
Renal carcinoma is a common and frequently fatal carcinoma occurring worldwide and death rates due to this carcinoma are increasing with time. In the present study, we investigated the potential of thymoquinone a natural compound to induce apoptosis in renal carcinoma Caki cells. Thymoquinone efficiently enhanced the apoptotic population of Caki cells in a dose-dependent manner. Moreover, thymoquinone-mediated apoptosis caused downregulation of c-FLIP and Bcl-2, the master regulators of the anti-apoptotic mechanism. However, we did not find any changes in mRNA expression level of c-FLIP, therefore; this regulation of c-FLIP was a result of post-translation modification by thymoquinone. In contrast, expression of the $\mathrm{Bcl}-2$ protein was observed at both transcriptional and translational level. However, we also observed that thymoquinone enhanced the level of intracellular reactive oxygen species (ROS) in Caki cells, which resulted in reduction of mitochondrial membrane potential (MMP) and cytochrome $c$ release into cytoplasm. Our results postulate that thymoquinone induces apoptosis through downregulating c-FLIP and Bcl-2 which can be utilized as a chemotherapeutic agent to treat renal carcinoma.
\end{abstract}

\section{Introduction}

There are various kidney-related malignancies, yet, renal cell carcinoma is the most frequenty occurring tumor among these. These tumor types are not responsive to chemotherapy or radiation therapy $(1,2)$, thus, it is extremely hard to treat

Correspondence to: Dr Taeg Kyu Kwon, Department of Immunology, School of Medicine, Keimyung University, 2800 Dalgubeoldaero, Dalseo-Gu, Daegu 704-701, Republic of Korea E-mail: kwontk@dsmc.or.kr

Key words: thymoquinone, c-FLIP, Bcl-2, apoptosis, renal cell carcinoma them and this is the motivation why different groups of researchers are attempting to acquaint some novel chemotherapeutic agent that can treat this disease. Although, there have been many efforts to treat this carcinoma with molecular or gene therapy, for example, tyrosine kinase inhibitors, mammalian target of rapamycin (mTOR) and vascular endothelial growth factor (VEGF) inhibitors (3), the pharmacological agents that can play an important role in inhibition of these genes are the most important. However, the mechanism underlying the initiation to the progression of most cancers is similar to each other for example, there are various master regulators of anti-apoptotic mechanism such as Bcl-2 and c-FLIP that limit the potential of a drug to initiate apoptosis mechanism within the cell $(4,5)$.

In light of the fact that renal carcinoma is one of the most deadly types of cancers, some candidates have been introduced to stop and/or limit the progression of the metastasis of this carcinoma, for example, sunitinib and pazopanib, drugs that are reported to be the inhibitors of tyrosine kinase $(6,7)$. Indeed, these agents were found to be able to stop the growth of cancer cells but extensive research on these agents revealed that they are associated with drug resistance and they have various side-effects as well $(8,9)$. Therefore, there is a need to introduce potent candidates that are originated from a natural source and are not destructive to the normal physiological condition of cells or tissue.

Thymoquinone is a natural polyphenolic compound found abundantly in black cumin (Nigella sativa L.) seeds and is grouped as monoterpenes. Thymoquinone has recently been reported for its various medicinal properties, for example, it is effective to treat gastroenteritis and various other organ and cell-associated inflammation $(10,11)$. Moreover, few recent studies explored its efficacy to kill cancer cells via induction of apoptosis mechanism, and some researchers demonstrated that thymoquinone has potential to reduce the volume of breast, colon and gastric cancer using in vivo model $(12,13)$, however, very limited studies have been carried out to uncover its mechanism of action in renal carcinoma cell lines.

In the present study, we have evaluated the efficacy of thymoquinone against Caki cells, a renal carcinoma cell line and uncovered its molecular mechanism of action against this cell line. 


\section{Materials and methods}

Cells and materials. Caki, A498 and ACHN cells were obtained from the American Type Culture Collection (ATCC; Manassas, VA, USA). The culture medium used throughout these experiments was Dulbecco's modified Eagle's medium (DMEM) containing 10\% fetal bovine serum (FBS), $20 \mathrm{mM}$ HEPES buffer and $100 \mu \mathrm{g} / \mathrm{ml}$ gentamycin. The mouse kidney cells, TMCK-1, were a gift from Dr T.J. Lee (Yeungnam University, Korea). z-VAD-fmk was purchased from R\&D Systems. Thymoquinone was purchased from Sigma Chemical Co. (St. Louis, MO, USA). Anti-Bcl-2 (sc-783), anti-Bcl-xL (sc-634), anti-Mcl-1 (sc-819) and anti-cIAP2 (sc-7944) were purchased from Santa Cruz Biotechnology (Santa Cruz, CA, USA). Anti-XIAP (610762) was purchased from BD Biosciences (Bedford, MA, USA). Anti-PARP (\#9542) antibody was obtained from Cell Signaling Technology (Beverly, MA, USA). Anti-actin (A5441) antibody was obtained from Sigma (St. Louis, MO, USA). Other reagents were purchased from Sigma Chemical Co.

Flow cytometric analysis. For flow cytometry, the cells were resuspended in $100 \mu$ l of phosphate-buffered saline (PBS), and $200 \mu 1$ of $95 \%$ ethanol was added while the cells were being vortexed. The cells were then incubated at $4^{\circ} \mathrm{C}$ for $1 \mathrm{~h}$, washed with PBS, resuspended in $250 \mu 1$ of $1.12 \%$ sodium citrate buffer ( $\mathrm{pH}$ 8.4) with $12.5 \mu \mathrm{g}$ of RNase and incubated for an additional $30 \mathrm{~min}$ at $37^{\circ} \mathrm{C}$. The cellular DNA was then stained by adding $250 \mu \mathrm{l}$ of a propidium iodide solution $(50 \mu \mathrm{g} / \mathrm{ml})$ to the cells for $30 \mathrm{~min}$ at room temperature (14). The stained cells were analyzed by fluorescent-activated cell sorting on a FACScan flow cytometer to determine the relative DNA content, which was based on the red fluorescence intensity.

Western blot analysis. For the western blot experiments, the cells were washed with cold PBS and lysed on ice in modified RIPA buffer (50 mM Tris-HCl pH 7.4, $1 \%$ NP-40, $0.25 \%$ Na-deoxycholate, $150 \mathrm{mM} \mathrm{NaCl}, 1 \mathrm{mM} \mathrm{Na}_{3} \mathrm{VO}_{4}$ and $1 \mathrm{mM}$ $\mathrm{NaF})$ containing protease inhibitors $(100 \mu \mathrm{M}$ phenylmethylsulfonyl fluoride, $10 \mu \mathrm{g} / \mathrm{ml}$ leupeptin, $10 \mu \mathrm{g} / \mathrm{ml}$ pepstatin and $2 \mathrm{mM}$ EDTA). The lysates were centrifuged at $10,000 \mathrm{x} g$ for $10 \mathrm{~min}$ at $4^{\circ} \mathrm{C}$ and the supernatant fractions were collected. The proteins were separated by SDS-PAGE electrophoresis and transferred to Immobilon-P membranes. The specific proteins were detected using an enhanced chemiluminescence (ECL) western blotting kit according to the manufacturer's instructions.

DNA fragmentation assay. DNA fragmentation was performed using the Cell Death Detection ELISAPLUS kit (Boehringer Mannheim, Indianapolis, IN, USA). Briefly, cells were centrifuged for $10 \mathrm{~min}$ at $200 \mathrm{x} \mathrm{g}$, the supernatant was removed, and pellet was lysed for $30 \mathrm{~min}$. After centrifuging the plate again at $200 \mathrm{x}$ g for $10 \mathrm{~min}$, and the supernatant that contained the cytoplasmic histone-associated DNA fragments was collected and incubated with an immobilized anti-histone antibody. The reaction products were incubated with a peroxidase substrate for $5 \mathrm{~min}$ and measured by spectrophotometry at 405 and $490 \mathrm{~nm}$ (reference wavelength) with a microplate reader. The signals in the wells containing the substrate alone were subtracted as background.
Asp-Glu-Val-Asp-ase (DEVDase) activity assay. To evaluate DEVDase activity, cell lysates were prepared after their respective treatments with thymoquinone. Assays were performed in 96-well microtiter plates by incubating $20 \mathrm{mg}$ of cell lysates in $100 \mu \mathrm{l}$ of reaction buffer (1\% NP-40, $20 \mathrm{mM}$ Tris-HCl, pH 7.5, $137 \mathrm{mM} \mathrm{NaCl}, 10 \%$ glycerol) containing a caspase substrate [Asp-Glu-Val-Asp-chromophore-p-nitroanilide (DVAD-pNA)] at $5 \mathrm{mM}$. Lysates were incubated at $37^{\circ} \mathrm{C}$ for $2 \mathrm{~h}$. Thereafter, the absorbance at $405 \mathrm{~nm}$ was measured with a spectrophotometer.

$R N A$ isolation, reverse transcription polymerase chain reaction (RT-PCR). Total cellular RNA was extracted from cells using TRIzol reagent (Life Technologies, Gaithersburg, MD, USA). Complementary DNA was synthesized from $2 \mu \mathrm{g}$ of total RNA using M-MLV reverse transcriptase (Promega, Madison, WI, USA). The cDNA for c-FLIP, Bcl-2 and actin were amplified by a PCR using specific primers: c-FLIP (forward) 5'-CGG ACT ATA GAG TGC TGA TGG-3' and (reverse) 5'-GAT TAT CAG GCA GAT TCC TAG-3'; Bcl-2 (forward) 5'-GTC CTC AGC CCT CGC TCT-3' and (reverse) 5'-CAC CTA ATT GGG CTC CAT CT-3'; actin (forward) 5'-GGC ATC GTC ACC AAC TGG GAC-3' and (reverse) 5'-CGA TTT CCC GCT CGG CCG TGG-3'. PCR products were analyzed by agarose gel electrophoresis and visualized using ethidium bromide staining.

Transfection and promoter activity assay. Transient transfection was performed in 6-well plates. One day before the transfection, Caki cells were plated at $\sim 60-80 \%$ confluence. The $\mathrm{Bcl}-2 /-3254$ promoter- or NF- $\mathrm{kB}-$ luciferase plasmid was transfected into the cells using Lipofectamine ${ }^{\mathrm{TM}} 2000$ (Invitrogen, Carlsbad, CA, USA). To assess the promoter-driven expression of the luciferase gene, the cells were collected and disrupted by sonication in lysis buffer ( $25 \mathrm{mM}$ Tris-phosphate $\mathrm{pH} 7.8$, 2 mM EDTA, $1 \%$ Triton X-100 and 10\% glycerol), and aliquots of the supernatants were used to analyze the luciferase activity according to the manufacturer's instructions (Promega).

Measurement of reactive oxygen species (ROS). Intracellular accumulation of ROS was determined using the fluorescent probes 2',7'-dichlorodihydrofluorescein diacetate (H2DCFDA). H2DCFDA is commonly used to measure ROS generation. Caki cells were pretreated with NAC for $30 \mathrm{~min}$, and then added with thymoquinone. Cells were stained with the fluorescent dye H2DCFDA for an additional $10 \mathrm{~min}$. Then, cells were observed using a fluorescence microscope (Axiovert 200M; Carl Zeiss, Oberkochen, Germany).

Determination for the mitochondrial membrane potential (MMP) by Rhodamine 123 and DiOC $_{6}$. Rhodamine 123 and $\mathrm{DiOC}_{6}$ (Molecular Probes, Carlsbad, CA, USA) uptake by mitochondria is directly proportional to its membrane potential. Caki cells $4 \mathrm{~h}$ after treatment were incubated with Rhodamine $123(5 \mu \mathrm{M})$ and $\mathrm{DiOC}_{6}$ for $30 \mathrm{~min}$ in the dark at $37^{\circ} \mathrm{C}(15)$. The cells were harvested and suspended in PBS. The MMP was subsequently analyzed using a flow cytometer (Becton-Dickinson, Franklin Lakes, NJ, USA).

Analysis of cytochrome c release. Caki cells $\left(1.2 \times 10^{6}\right.$ cells $\left./ \mathrm{ml}\right)$ were harvested, washed once with ice-cold PBS and gently 

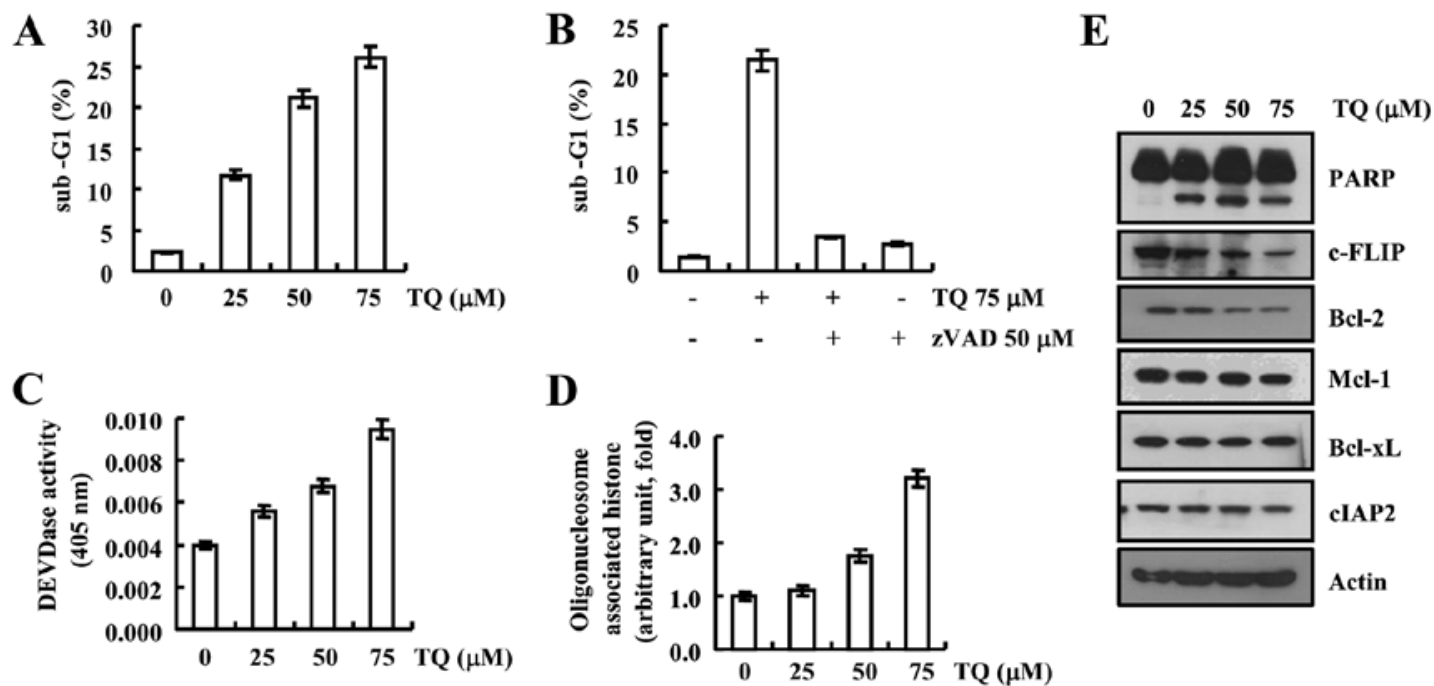

Figure 1. Thymoquinone induces apoptosis in Caki cells. (A) Cells were treated with the indicated concentrations of thymoquinone for 24 h. Apoptosis was analyzed as a sub-G1 fraction by FACS. (B) Caki cells were pretreated with $25 \mu \mathrm{M}$ z-VAD-fmk for 30 min, and then $75 \mu \mathrm{M}$ thymoquinone was added for $24 \mathrm{~h}$. Apoptosis was analyzed as a sub-G1 fraction by FACS. (C) Caki cells were treated with the indicated concentrations of thymoquinone for 24 h. Caspase activities were determined with colorimetric assays using caspase-3 DEVDase assay kits. (D) DNA fragmentation in Caki cells was determined by the DNA fragmentation detection kit. (E) Cells were treated with the indicated concentrations of thymoquinone for $24 \mathrm{~h}$. Equal amounts of cell lysates (60 $\mu \mathrm{g})$ were subjected to electrophoresis and analyzed by western blotting for PARP, c-FLIP, Bcl-2, Mcl-1, Bcl-xL, cIAP2 and actin as a control for protein loading.

lysed for $2 \mathrm{~min}$ in $80 \mu \mathrm{l}$ ice-cold lysis buffer [250 $\mathrm{mM}$ sucrose, $1 \mathrm{mM}$ EDTA, 20 mM Tris-HCl (pH 7.2), $1 \mathrm{mM}$ DTT, $10 \mathrm{mM}$ $\mathrm{KCl}, 1.5 \mathrm{mM} \mathrm{MgCl}{ }_{2}, 5 \mu \mathrm{g} / \mathrm{ml}$ pepstatin A, $10 \mu \mathrm{g} / \mathrm{ml}$ leupeptin and $2 \mu \mathrm{g} / \mathrm{ml}$ aprotinin]. Lysates were centrifuged at $12,000 \mathrm{x} \mathrm{g}$ at $4^{\circ} \mathrm{C}$ for $10 \mathrm{~min}$ to obtain the supernatants (cytosolic extracts free of mitochondria) and the pellets (fraction that contains mitochondria). The resulting cytosolic fractions were used for western blot analysis with an anti-cytochrome $c$ antibody.

Statistical analysis. The data were analyzed using a one-way ANOVA followed by post hoc comparisons (Student-NewmanKeuls) using the Statistical Package for Social Sciences version 22.0 (SPSS, Inc., Chicago, IL, USA).

\section{Results}

Thymoquinone efficiently induces apoptosis in Caki cells. We first determined the cytotoxic effect of thymoquinone against Caki cells and found that after treatment of thymoquinone (25, 50 and $75 \mu \mathrm{M}$ ) for $24 \mathrm{~h}$ apoptotic population (sub-G1) was increased in a dose-dependent manner (Fig. 1A). Furthermore, we used caspase inhibitor zVAD to examine the association of caspases in apoptosis induced by thymoquinone, and we found that after inhibition of caspase apoptotic population was decreased even at a higher concentration of thymoquinone which was further validated by DEVDase activity suggesting that thymoquinone induced caspase-dependent apoptosis (Fig. 1B and C). Moreover, the level of cytoplasmic histone was observed to be increased that is an outcome of DNA fragmentation thus thymoquinone-induced DNA fragmentation which resulted in increased cytoplasmic histone (Fig. 1D). We further determined the expression pattern of apoptotic and anti-apoptotic proteins to understand the molecular mechanism underlying the thymoquinone toxicity, as depicted in Fig. 1E, thymoquinone enhanced the cleavage of PARP protein in a dose-dependent manner. Expression of anti-apoptotic proteins such as c-FLIP and Bcl-2 was downregulated, but expression of Mcl-1, Bcl-xL and cIAP2 did not change in western blot examination (Fig. 1E).

Thymoquinone downregulates c-FLIP expression to induce apoptosis in Caki cells. We found that thymoquinone downregulated the expression of c-FLIP in our previous experiment, next we decided to validate our data. We then examined the expression pattern of c-FLIP at the transcriptional level, results of RT-PCR analysis showed that there was no any change in the expression of c-FLIP at the transcriptional level (Fig. 2A). Therefore, we investigated whether thymoquinone modulates the protein stability of c-FLIP in Caki cells. Cells were treated with cycloheximide (CHX), an inhibitor of de novo protein synthesis, in the presence or absence of thymoquinone. CHX gradually decreased c-FLIP, but co-treatment with $\mathrm{CHX}$ and thymoquinone reduced more c-FLIP protein expression (Fig. 2B). To investigate the importance of downregulation of c-FLIP expression on thymoquinone-induced apoptosis, c-FLIP protein was overexpressed in Caki cells. Overexpression of c-FLIP markedly inhibited thymoquinone-induced increase of sub-G1 cell population (Fig. 2C) and PARP cleavage (Fig. 2D). These results indicate that downregulation of c-FLIP may be involved in thymoquinone-mediated apoptosis.

Expression of Bcl-2 is downregulated after treatment with thymoquinone through hindering the $N F-\kappa B$ cascade. We evaluated the effect of thymoquinone on the expression pattern of Bcl-2, another major regulator of the anti-apoptotic mechanism. Results are depicted in Fig. 3, where we first determined the expression of $\mathrm{Bcl}-2$ at the transcriptional level and found that Bcl-2 mRNA expression was reduced in a dose-dependent manner (Fig. 3A). Furthermore, we validated 
A

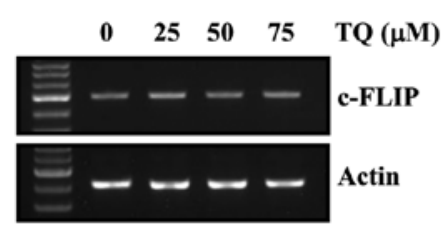

B

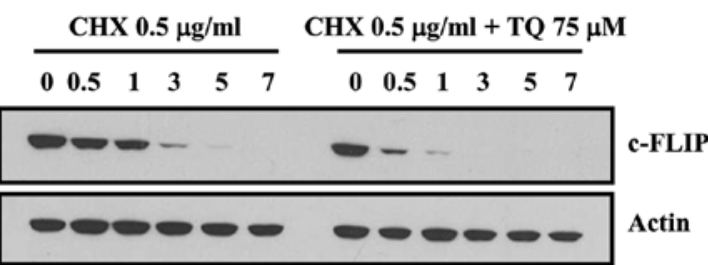

C
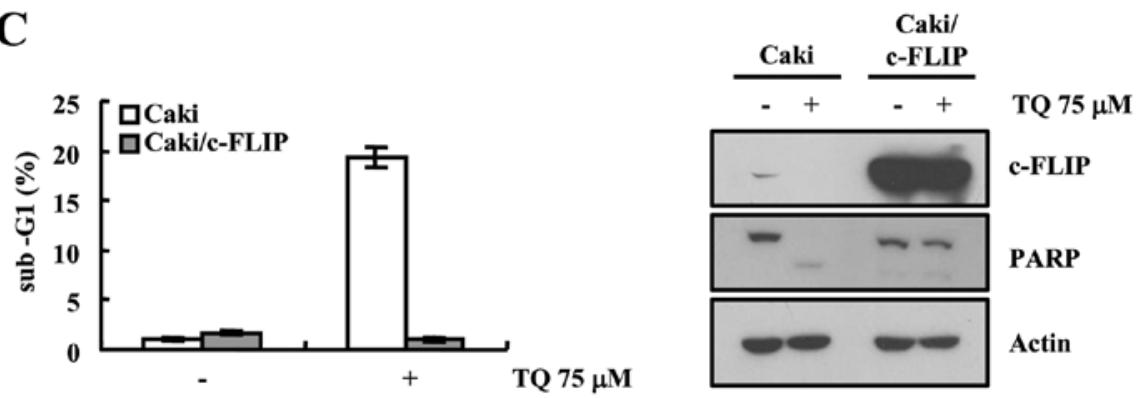

Figure 2. Thymoquinone downregulates c-FLIP protein at the post-transcriptional level in Caki cells. (A) Caki cells were treated with the indicated concentrations of thymoquinone for $24 \mathrm{~h}$. c-FLIP and actin mRNA expression was determined using RT-PCR. (B) Caki cells were treated with cyclohexamide (CHX) $20 \mu \mathrm{g} / \mathrm{ml}$ alone or $\mathrm{CHX}$ plus $75 \mu \mathrm{M}$ thymoquinone for indicated time periods. Equal amounts of cell lysates (60 $\mu \mathrm{g})$ were subjected to electrophoresis and analyzed by western blotting for c-FLIP and actin as a control for protein loading. (C) Vector (Caki/Vec) and c-FLIP overexpressed cells (Caki/cFLIP) were treated with $75 \mu \mathrm{M}$ thymoquinone for $24 \mathrm{~h}$. Apoptosis was analyzed as a sub-G1 fraction by FACS. Equal amounts of cell lysates (60 $\mu \mathrm{g})$ were subjected to electrophoresis and analyzed by western blotting for c-FLIP and actin as a control for protein loading. The data represent three independent experiments.

A

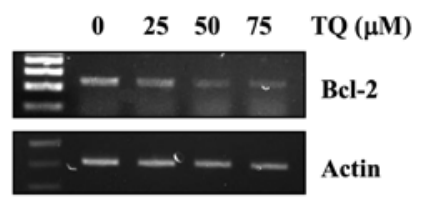

$\mathrm{C}$

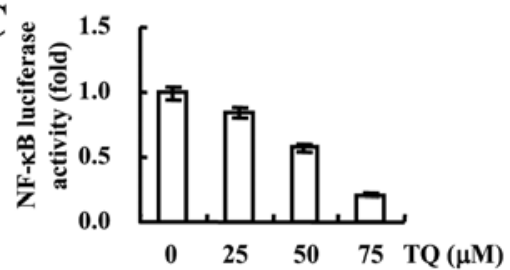

$\mathbf{E}$

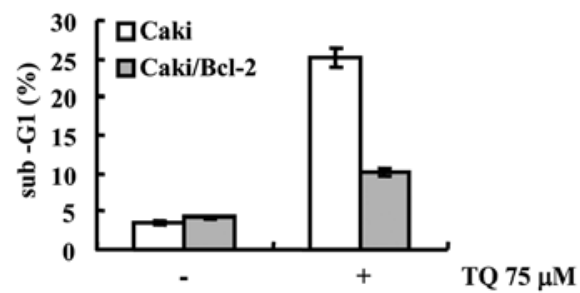

B

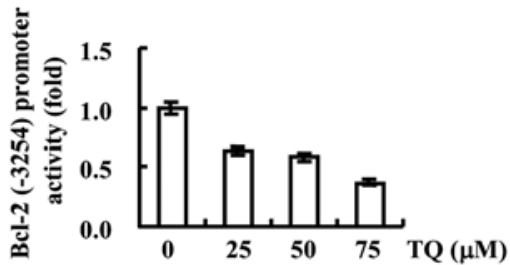

D

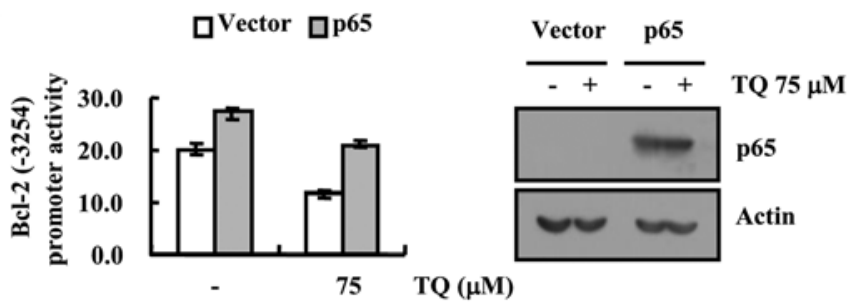

Figure 3. Thymoquinone downregulates Bcl-2 expression at the transcriptional level in Caki cells. (A) Caki cells were treated with the indicated concentrations of thymoquinone for $24 \mathrm{~h}$. Bcl-2 and actin mRNA expression were determined using RT-PCR. (B) Caki cells were transiently transfected with a plasmid harboring the luciferase gene under the control of the Bcl-2/-3254 promoter. After transfection, the Caki cells were treated with the indicated concentrations of thymoquinone for $24 \mathrm{~h}$. After treatment, the cells were lysed, and the luciferase activity was analyzed. (C) Caki cells were transiently transfected with NF- $\mathrm{BB}-$ luciferase construct. After transfection, the Caki cells were treated with the indicated concentrations of thymoquinone for $24 \mathrm{~h}$. After treatment, the cells were lysed and the luciferase activity was analyzed. (D) Caki cells were transiently co-transfected with NF-kB subunit (p65) and Bcl-2-luciferase construct. After transfection, the Caki cells were treated with $75 \mu \mathrm{M}$ thymoquinone for $24 \mathrm{~h}$. After treatment, the cells were lysed, and the luciferase activity was analyzed. Equal amounts of cell lysates $(60 \mu \mathrm{g})$ were subjected to electrophoresis and analyzed by western blotting for p65 and actin as a control for protein loading. (E) Vector $(\mathrm{Caki} / \mathrm{Vec})$ and Bcl-2 overexpressed cells (Caki/Bcl-2) were treated with $75 \mu \mathrm{M}$ thymoquinone for $24 \mathrm{~h}$. Apoptosis was analyzed as a sub-G1 fraction by FACS. Equal amounts of cell lysates $(60 \mu \mathrm{g})$ were subjected to electrophoresis and analyzed by western blotting for PARP, Bcl-2 and actin as a control for protein loading. The values in $(B, C, D$ and $E)$ represent the mean \pm SD from three independent samples. 
our data with Bcl-2 promoter assay and found that thymoquinone reduced the $\mathrm{Bcl}-2$ promoter activity in a dose-dependent manner (Fig. 3B). Moreover, we determined the effect of thymoquinone on $\mathrm{NF}-\kappa \mathrm{B}$ expression as it is associated with expression of $\mathrm{Bcl}-2$ protein. $\mathrm{NF}-\kappa \mathrm{B}$ luciferase activity was reduced after treatment of thymoquinone. In addition, overexpression of p65, a subunit of NF- $\mathrm{BB}$ heightened the $\mathrm{Bcl}-2$ promoter activity in case of thymoquinone treated cells, which was further confirmed by immunoblot analysis (Fig. 3D). We examined the efficacy of thymoquinone to induce apoptosis in Bcl-2 overexpressed Caki cells and observed that overexpression of Bcl-2 reversed the apoptotic potential of thymoquinone as evidenced by flow cytometric analysis (Fig. 3E). Moreover, thymoquinone-induced cleavage of PARP protein was blocked in Bcl-2 overexpressed cells (Fig. 3E), suggesting the downregulation of Bcl-2 plays a critical role in thymoquinoneinduced apoptosis.

Thymoquinone-induced ROS generation resulting in loss of MMP in Caki cells. The induction of ROS production plays an important role in apoptosis. Therefore, we carried out H2DCFDA staining to determine the level of intracellular ROS. Thymoquinone $(75 \mu \mathrm{M})$ potentially induced the generation of intracellular ROS within $10 \mathrm{~min}$, and then slightly reduced after $30 \mathrm{~min}$ of treatment (Fig. 4A and B). Furthermore, we determined the effect of thymoquinoneinduced ROS on cell death with or without using the ROS scavenger $N$-acetylcysteine (NAC). Thymoquinone-induced ROS generation caused apoptosis in Caki cells which was reduced after using the ROS scavenger (Fig. 4C). We observed increased intensity of MitoSOX Red dye which detects mitochondrial ROS production (Fig. 4D). Furthermore, we determined the MMP, as the exaggerated production of ROS leads to the mitochondrial damage. Rhodamine 123 and $\mathrm{DiOC}_{6}$ fluorometry data revealed the loss of MMP in time-dependent manner at $75 \mu \mathrm{M}$ thymoquinone treatment (Fig. 4E and F). Treatment with thymoquinone caused cytochrome $c$ release into cytoplasm (Fig. 4G). These results suggest that thymoquinone reduces the MMP levels and induces cytochrome $c$ release.

Thymoquinone exhibits cytotoxic effect against various renal carcinoma cells, but not in normal cells. Although, our results demonstrated that thymoquinone potentially induced apoptosis in Caki cells, we further examined the efficacy of thymoquinone against other renal carcinoma cell line for example ACHN and A498 and found that thymoquinone has efficacy to induce apoptosis in all the renal carcinoma cells used in the present study (Fig. 5A and B). However, there was the insignificant cytotoxic effect of thymoquinone on normal TMCK-1 cells neither on both morphology and cell population analysis, even at a higher concentration of $75 \mu \mathrm{M}$ which induced the apoptosis in Caki cells (Fig. 5C and D) suggesting the safe use of thymoquinone.

\section{Discussion}

There is an intricate balance between pro- and anti-apoptotic proteins in normal cells; however, in cancer cells there is a dysregulation of this balance and that may be due to overex- pression of anti-apoptotic proteins which demise the process of apoptosis (16), for instance, overexpression of Bcl-2, an antiapoptotic protein, protects the apoptosis of prostate cancer cells (17). Consequently, in the present study we evaluated for example the apoptotic PARP as well as the anti-apoptotic (c-FLIP, Bcl-2, Mcl-1, Bcl-xL and cIAP2) markers through immunoblot analysis and observed that thymoquinone treatment induced the cleavage of PARP and downregulation of c-FLIP and Bcl-2 proteins.

c-FLIP is a master regulator of anti-apoptotic mechanism and is found to be abundantly expressed in a variety of cancer cells (18). Overexpression of c-FLIP interferes with caspase- 8 protein and is able to block the cleavage of caspase- 8 which ultimately terminates the apoptotic machinery (4). Thymoquinone downregulated the expression of c-FLIP at translation level but surprisingly there was no effect of thymoquinone on transcriptional regulation of c-FLIP, however, it is well documented in literature that ROS contribute to post-translation modification of c-FLIP, through upregulation of proteasomal activity $(19,20)$. Notably, we found that thymoquinone potentially induced production of intracellular ROS in Caki cells, thus, we hypothesize that this property of thymoquinone may be responsible for the downregulation of c-FLIP.

Another key regulator protein of anti-apoptotic machinery is Bcl-2 (21-23), and in the present study, we found that thymoquinone potentially suppressed the expression of this protein at both transcriptional and translation level resulting in the initiation of the apoptotic cascade. However, recently numerous studies have explored the association of $\mathrm{NF}-\kappa \mathrm{B}$ with $\mathrm{Bcl}-2$, for example, expression of the $\mathrm{NF}-\kappa \mathrm{B}$ targets BCL-2 expression on the transcriptional level $(24,25)$. We, therefore, examined the possible role of thymoquinone in the regulation of $\mathrm{NF}-\kappa \mathrm{B}$ activity and notably, a highly decreased $\mathrm{NF}-\kappa \mathrm{B}$ activity was observed in luciferase reporter assay in a concentration-dependent manner suggesting $\mathrm{NF}-\kappa \mathrm{B}$ inhibitory efficacy of thymoquinone. In contrast, when we overexpressed p65, a subunit of NF- $\mathrm{B}$ it caused increased promoter activity of $\mathrm{Bcl}-2$ even at a higher concentration of thymoquinone which clearly indicates that downregulation of Bcl-2 by thymoquinone was associated with $\mathrm{NF}-\kappa \mathrm{B}$ activity. Heckman et al (25) reported similar results in lymphoma cells where overexpression of $\mathrm{NF}-\kappa \mathrm{B}$ was responsible for the Bcl-2 overexpression, taken together, we can conclude that hindrance in $\mathrm{NF}-\kappa \mathrm{B}$ activity may be an effective tool to target the Bcl-2 expression which was accomplished by thymoquinone in our case.

We further evaluated the effect of thymoquinone on MMP, as we found that thymoquinone potentially downregulated Bcl-2 expression which in turn is associated with the loss of MMP leading to mitochondrial death, a potent and common anticancer target for many pharmacological agents (26-28). In addition, a well-known inducer of mitochondrial stress is generation of exaggerated ROS inside the cell which eventually kill the mitochondria (29-31). Interestingly, both the phenomenon associated with mitochondrial stress (Bcl-2 downregulation and ROS generation) were found to be followed by thymoquinone in the present study, thus, we examined the mitochondrial membrane potential (MMP) in the presence of thymoquinone and as expected, the loss of MMP 
$\mathbf{A}$

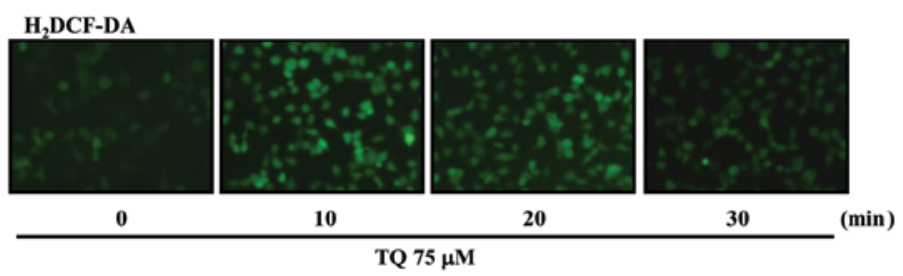

C
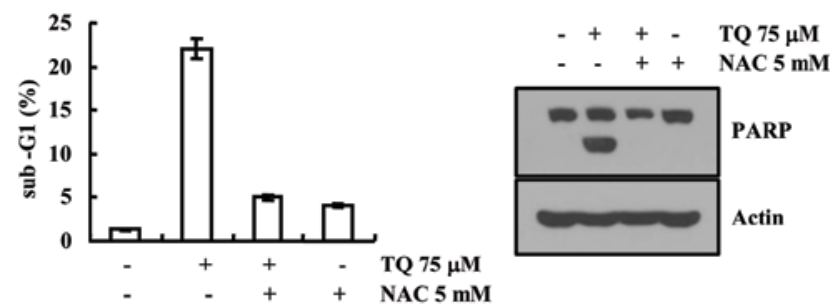

$\mathbf{E}$

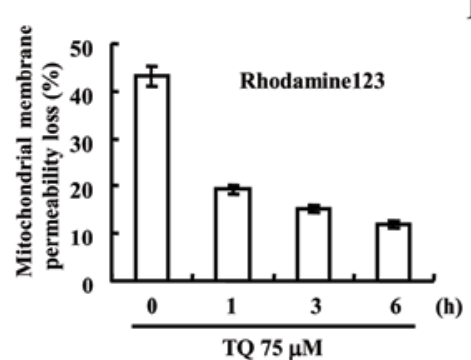

B

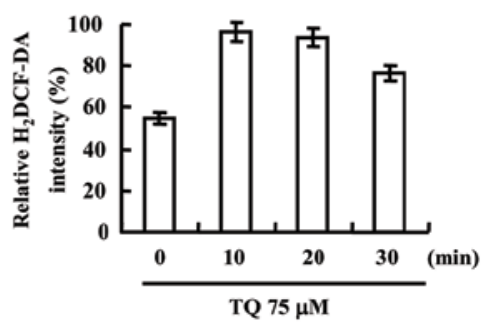

D

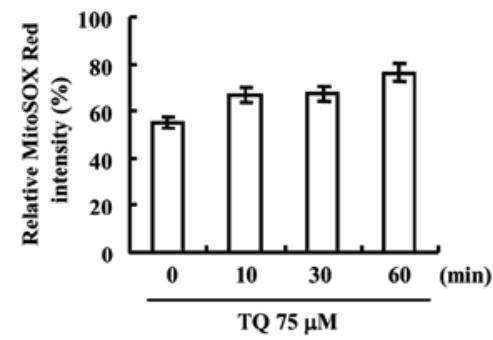

G

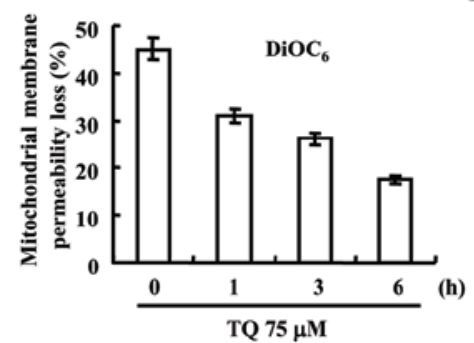

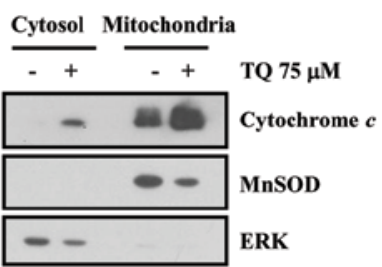

Figure 4. Thymoquinone induces ROS and release of cytochrome $c$ into the cytoplasm. (A and B) Caki cells were stimulated with $75 \mu \mathrm{M}$ thymoquinone for the indicated time points and loaded with a H2DCF-DA fluorescent dye. H2DCF-DA fluorescence intensity was detected by (A) fluorescence microscopy and (B) FACS. (C) Caki cells were pretreated with NAC (5 mM) for $30 \mathrm{~min}$, and then stimulated with $75 \mu \mathrm{M}$ thymoquinone for $24 \mathrm{~h}$. Apoptosis was analyzed as the sub-G1 population by FACS analysis. Equal amounts of cell lysates $(60 \mu \mathrm{g})$ were subjected to electrophoresis and analyzed by western blotting for PARP and actin as a control for protein loading. The data represent three independent experiments. (D) Caki cells were stimulated with $75 \mu \mathrm{M}$ thymoquinone for the indicated time points and loaded with a MitoSOX Red dye. Fluorescence intensity was detected by FACS. (E and F) Caki cells were treated with $75 \mu \mathrm{M}$ thymoquinone for $4 \mathrm{~h}$. The mitochondrial membrane potential was measured as described under 'Materials and methods'. The data represent three independent experiments. (G) Caki cells were treated with $75 \mu \mathrm{M}$ thymoquinone for $4 \mathrm{~h}$. Cytosol fraction and mitochondria fraction (Mito). Extracts were prepared as described under 'Materials and methods'. Equal amounts of cell lysates $(40 \mu \mathrm{g})$ were subjected to electrophoresis and analyzed by western blotting for cytochrome $c$ and ERK as a control for protein loading (right panel). To show there is no mitochondrial contamination in the cytosol fraction, we carried out western blot analysis using antibody against MnSOD that was expressed in mitochondria. Mitochondrial fraction derived from non-treated cells was used as a positive control.

A

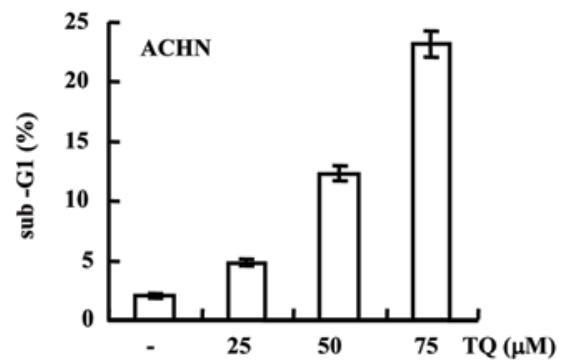

B

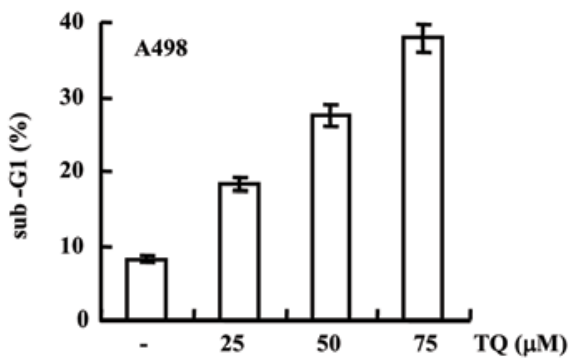

C

Caki

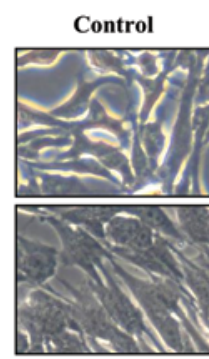

TQ $25 \mu \mathrm{M}$

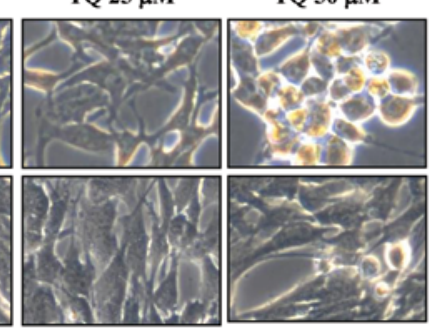

TQ $75 \mu \mathrm{M}$

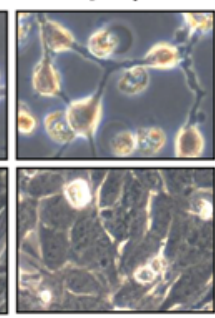

D

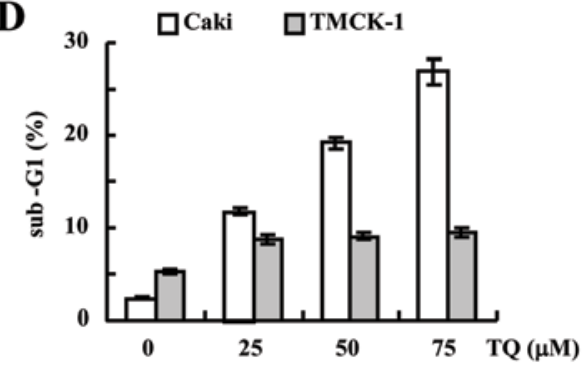

Figure 5. Thymoquinone induces apoptosis in other renal carcinoma cells, but not in normal cells. Renal carcinoma (A) ACHN and (B) A498 cells were treated with the indicated concentrations of thymoquinone for $24 \mathrm{~h}$. Apoptosis was analyzed as a sub-G1 fraction by FACS. (C) TMCK-1 and Caki cells were treated with the indicated concentrations of thymoquinone for $24 \mathrm{~h}$. The cell morphologies were determined by interference light microscopy. (D) Apoptosis was analyzed as the sub-G1 fraction by FACS analysis. Values in (A, B and D) are expressed as mean \pm SD of three independent experiments. 
was the outcome of the experiment with an intense release of cytochrome $c$ into cytosol, a defining feature of mitochondrial damage (31). However, undoubtedly, a potent candidate for anticancer therapy should be one which possess toxic effect against cancer cells but not to normal cells and we in the case of thymoquinone found similar results showing insignificant toxic effect on normal cells (TMCK-1 cells).

On account of the results obtained in the present study, we conclude that thymoquinone has potential to induce apoptosis in renal cell carcinoma with a major mechanism of c-FLIP and Bcl-2 downregulation. In addition, it is able to induce mitochondrial dysfunctioning through the generation of intracellular ROS in Caki cells which eventually leads to cell death. Moreover, it originates from natural plants and its insignificant toxicity to the normal cells warrant its safe use as a drug against renal cell carcinoma. However, further experiments on an animal model is needed to evaluate its efficacy and precise mechanism in vivo.

\section{Acknowledgements}

The present study was supported by an NRF grant funded by the Korea Government (MSIP) (2014R1A5A2010008) and a 2015 Scholar Research Grant from Keimyung University.

\section{References}

1. Hodorová I, Rybárová S, Solár P, Vecanová J, Mihalik J, Bohus P, Mellová Y and Kluchová D: Multidrug resistance proteins in renal cell carcinoma. Folia Biol 54: 187-192, 2008.

2. Motzer RJ, Russo P, Nanus DM and Berg WJ: Renal cell carcinoma. Curr Probl Cancer 21: 185-232, 1997.

3. Rini BI and Atkins MB: Resistance to targeted therapy in renal-cell carcinoma. Lancet Oncol 10: 992-1000, 2009.

4. Park EJ, Min KJ, Choi KS and Kwon TK: Dicoumarol sensitizes renal cell carcinoma Caki cells to TRAIL-induced apoptosis through down-regulation of $\mathrm{Bcl}-2, \mathrm{Mcl}-1$ and c-FLIP in a NQO1-independent manner. Exp Cell Res 323: 144-154, 2014.

5. Han MA, Woo SM, Min KJ, Kim S, Park JW, Kim DE, Kim SH, Choi YH and Kwon TK: 6-Shogaol enhances renal carcinoma Caki cells to TRAIL-induced apoptosis through reactive oxygen species-mediated cytochrome $c$ release and down-regulation of c-FLIP(L) expression. Chem Biol Interact 228: 69-78, 2015.

6. Motzer RJ, Hutson TE, Cella D, Reeves J, Hawkins R, Guo J, Nathan P, Staehler M, de Souza P, Merchan JR, et al: Pazopanib versus sunitinib in metastatic renal-cell carcinoma. N Engl J Med 369: 722-731, 2013.

7. Keisner SV and Shah SR: Pazopanib: The newest tyrosine kinase inhibitor for the treatment of advanced or metastatic renal cell carcinoma. Drugs 71: 443-454, 2011.

8. Gotink KJ, Rovithi M, de Haas RR, Honeywell RJ, Dekker H, Poel D, Azijli K, Peters GJ, Broxterman HJ and Verheul HM: Cross-resistance to clinically used tyrosine kinase inhibitors sunitinib, sorafenib and pazopanib. Cell Oncol 38: 119-129, 2015.

9. Juengel E, Kim D, Makarević J, Reiter M, Tsaur I, Bartsch G, Haferkamp A and Blaheta RA: Molecular analysis of sunitinib resistant renal cell carcinoma cells after sequential treatment with RAD001 (everolimus) or sorafenib. J Cell Mol Med 19: 430-441, 2015.

10. Salomi MJ, Nair SC and Panikkar KR: Inhibitory effects of Nigella sativa and saffron (Crocus sativus) on chemical carcinogenesis in mice. Nutr Cancer 16: 67-72, 1991.

11. Tiruppur Venkatachallam SK, Pattekhan H, Divakar S and Kadimi US: Chemical composition of Nigella sativa L. seed extracts obtained by supercritical carbon dioxide. J Food Sci Technol 47: 598-605, 2010
12. Lei X, Lv X, Liu M, Yang Z, Ji M, Guo X and Dong W: Thymoquinone inhibits growth and augments 5-fluorouracilinduced apoptosis in gastric cancer cells both in vitro and in vivo. Biochem Biophys Res Commun 417: 864-868, 2012.

13. Gali-Muhtasib H, Roessner A and Schneider-Stock R: Thymoquinone: A promising anti-cancer drug from natural sources. Int J Biochem Cell Biol 38: 1249-1253, 2006.

14. Mi Y, Zhang C, Bu Y, Zhang Y, He L, Li H, Zhu H, Li Y, Lei Y and Zhu J: DEPDC1 is a novel cell cycle related gene that regulates mitotic progression. BMB Rep 48: 413-418, 2015.

15. Seo K, Ki SH and Shin SM: Methylglyoxal induces mitochondrial dysfunction and cell death in liver. Toxicol Res 30: 193-198, 2014.

16. Wong RS: Apoptosis in cancer: From pathogenesis to treatment. J Exp Clin Cancer Res 30: 87, 2011.

17. Raffo AJ, Perlman H, Chen MW, Day ML, Streitman JS and Buttyan R: Overexpression of bcl-2 protects prostate cancer cells from apoptosis in vitro and confers resistance to androgen depletion in vivo. Cancer Res 55: 4438-4445, 1995.

18. Shirley S and Micheau O: Targeting c-FLIP in cancer. Cancer Lett 332: 141-150, 2013.

19. Wilkie-Grantham RP, Matsuzawa S and Reed JC: Novel phosphorylation and ubiquitination sites regulate reactive oxygen species-dependent degradation of anti-apoptotic c-FLIP protein. J Biol Chem 288: 12777-12790, 2013.

20. Willis S, Day CL, Hinds MG and Huang DC: The Bcl-2-regulated apoptotic pathway. J Cell Sci 116: 4053-4056, 2003.

21. Czabotar PE, Lessene G, Strasser A and Adams JM: Control of apoptosis by the BCL-2 protein family: Implications for physiology and therapy. Nat Rev Mol Cell Biol 15: 49-63, 2014.

22. Labi V, Grespi F, Baumgartner F and Villunger A: Targeting the Bcl-2-regulated apoptosis pathway by BH3 mimetics: A breakthrough in anticancer therapy? Cell Death Differ 15: 977-987, 2008.

23. Tracey L, Pérez-Rosado A, Artiga MJ, Camacho FI, Rodríguez A, Martínez N, Ruiz-Ballesteros E, Mollejo M, Martinez B Cuadros M, et al: Expression of the NF-kappaB targets BCL2 and BIRC5/Survivin characterizes small $\mathrm{B}$-cell and aggressive B-cell lymphomas, respectively. J Pathol 206: 123-134, 2005.

24. Catz SD and Johnson JL: Transcriptional regulation of bcl-2 by nuclear factor kappa B and its significance in prostate cancer. Oncogene 20: 7342-7351, 2001.

25. Heckman CA, Mehew JW and Boxer LM: NF-kappaB activates Bcl-2 expression in $\mathrm{t}(14 ; 18)$ lymphoma cells. Oncogene 21: 3898-3908, 2002.

26. Tang S, Hu J, Meng Q, Dong X, Wang K, Qi Y, Chu C, Zhang X and Hou L: Daidzein induced apoptosis via down-regulation of $\mathrm{Bcl}-2 / \mathrm{Bax}$ and triggering of the mitochondrial pathway in BGC-823 cells. Cell Biochem Biophys 65: 197-202, 2013.

27. Chen QY, Lu GH, Wu YQ, Zheng Y, Xu K, Wu LJ, Jiang ZY, Feng $R$ and Zhou JY: Curcumin induces mitochondria pathway mediated cell apoptosis in A549 lung adenocarcinoma cells. Oncol Rep 23: 1285-1292, 2010.

28. Slimen IB, Najar T, Ghram A, Dabbebi H, Ben Mrad M and Abdrabbah M: Reactive oxygen species, heat stress and oxidative-induced mitochondrial damage. A review. Int $\mathrm{J}$ Hyperthermia 30: 513-523, 2014.

29. Fleury C, Mignotte B and Vayssière JL: Mitochondrial reactive oxygen species in cell death signaling. Biochimie 84: 131-141, 2002 .

30. Cai J, Yang J and Jones DP: Mitochondrial control of apoptosis: The role of cytochrome c. Biochim Biophys Acta 1366: 139-149, 1998.

31. Banjerdpongchai R, Kongtawelert P, Khantamat O, Srisomsap C, Chokchaichamnankit D, Subhasitanont $P$ and Svasti J: Mitochondrial and endoplasmic reticulum stress pathways cooperate in zearalenone-induced apoptosis of human leukemic cells. J Hematol Oncol 3: 50, 2010. 